\title{
OBSERVAÇÕES COMPLEMENTARES SÔBRE A PRESENÇA DO TOXOPLASMA GONDII NA SALIVA DE PACIENTES COM TOXOPLASMOSE *
}

\author{
Guido Carlos Levi **, Saburo Hyakutake ***, Vicente Amato Neto **** \\ e Marcelo O. A. Corrêa $* * * *$
}

\begin{abstract}
Através de inoculação no peritônio de camundongos, demonstraram os autores a presença do Toxoplasma gondii na saliva de $12(60 \%)$ individuos com toxoplasmose, em estudo no qual 20 doentes foram considerados.

Esta verificaçấo é comunicada como complementação a outra, anterior e preliminar, relativa ao mesmo assunto.

$A$ importância da presença do parasito na saliva mereceu destaque, em virtude do significado que ela pode ter em relação à transmissão da toxoplasmose.
\end{abstract}

\section{INTRODUÇÃO}

Em comunicação preliminar e anterior relatamos que, através de inoculação no peritônio de camundongos, demonstramos a presença do Toxoplasma gondii na saliva de nove pacientes com toxoplasmose. Utilizamos, nessa investigação, materiais obtidos de dez doentes, sendo que apenas um dêles correspondia à forma congênita da infecçāo, pois a qualificação de modalidade adquirida pôde ficar estabelecida quanto aos demais (2).

Nessa oportunidade, a importância dessa verificação foi salientada, uma vez que ela representa contribuição que talvez venha a esclarecer, de maneira significativa, alguns aspectos relativos à transmissāo da infecção.

Observações mais numerosas e complementares foram por nós efetuadas sôbre o assunto e, com a presente comunicação, apresentamos as novas verificaçōes que tivemos a ocasiāo de concretizar.

\section{MATERIAL E MÉTODOS}

A saliva de vinte indivíduos com toxoplasmose foi inoculada, pela via intraperitoneal, em camundongos albinos com 32 dias de idade e criados no biotério do Instituto Adolfo Lutz de São Paulo.

O diagnóstico da infecçāo nas pessoas consideradas decorreu sempre de confirmação fornecida pelo teste de Sabin-Feldman, positivo em diluição de $1 / 4.000$ ou maior, em época bem próxima à da obtenção do material a ser inoculado. Apenas um doente (caso n. ${ }^{0}$ ) fôra medicado especificamente em ocasiāo anterior, nāo recente, tendo sido a sulfadiazina, a pirimetamina e a espiramicina as drogas usadas. No Quadro, estăo assinalados as idades dos pacientes, os periodos de tempo de

*) Trabalho do Servico de Doencas Transmissiveis do Hospital do Servidor Público Estadual de São Paulo (Médico-chefe: Dr. Vicente Amato Neto) e da Seção de Parasitologia do Instituto Adolfo lutz de São Paulo (Médico-chefe: Dr. Marcelo O. A. Corrêa).

(**) Médico do Serviço de Doenças Transmissiveis.

(***) Biologista da Seção de Parasitologia.

(****) Médico-chefe do Serviço de Doenças Transmissiveis

$(* * * *)$ Médico-chefe da Seção de Parasitologia. 


\section{QUADRO}

Resultados de inoculações, no peritônio de camundongos, de salivas de pacientes com toxoplasmose

\begin{tabular}{|c|c|c|c|c|}
\hline Caso n? & $\begin{array}{c}\text { Idade } \\
\text { (em anos) }\end{array}$ & $\begin{array}{l}\text { Periodo de tempo } \\
\text { do duração das } \\
\text { manifestações } \\
\text { clinicas }\end{array}$ & $\begin{array}{l}\text { Forma elínica da } \\
\text { toxoplasmose }\end{array}$ & $\begin{array}{l}\text { Resultado } \\
\text { da } \\
\text { inoculacão }\end{array}$ \\
\hline 1.A.S.O. & 43 & 15 meses & Linfoglandular & $\mathbf{P}$ \\
\hline 2.M.P.O. & 15 & 3 meses & Linfoglandular & $\mathbf{P}$ \\
\hline 3-A.M.O. & 37 & 1 mês & Exame clinico normal; astenia & $\mathrm{P}$ \\
\hline 4-F.C.M.S. & 11 & 2 meses & $\begin{array}{l}\text { Exame clínico normal; febre } \\
\text { o cefaléia. }\end{array}$ & $\mathbf{P}$ \\
\hline 5-V.P.F. & 12 & 6 meses & Linfoglandular & $\mathbf{P}$ \\
\hline 6-M.P.V. & 15 & 20 dias & Linfoglandular & $\mathbf{P}$ \\
\hline 7-B.S.P. & 38 & Indeterminado & $\begin{array}{l}\text { Exame clinico normal, corior- } \\
\text { retinite; abortamentos re- } \\
\text { petidos; gravidez }\end{array}$ & $\mathrm{N}$ \\
\hline 8-J.F.T. & 42 & 45 dias & Linfoglandular & $\mathbf{P}$ \\
\hline 9.E.M. & 31 & 21 dias & Linfoglandular & $\mathbf{P}$ \\
\hline 10-A. ̋.H.C. & 11 & 11 dias & Congênita. & $\mathbf{P}$ \\
\hline 11-E.C. & 6 & 22 dias & Linfoglandular & $\mathrm{N}$ \\
\hline 12-M.G. & 5 & 5 anos & Congênita. & $N$ \\
\hline 13.F.M.J. & 12 & 2 meses & $\begin{array}{l}\text { Exame clínico normal; febre, } \\
\text { cefaléia e astenia }\end{array}$ & $\mathbf{P}$ \\
\hline
\end{tabular}


(continuação do Quadro)

\begin{tabular}{|c|c|c|c|c|}
\hline 14-F.O. & 49 & 9 meses & Coriorretinite & $\mathbf{N}$ \\
\hline 15-I. A, B. & 6 & Indeter minado & $\begin{array}{l}\text { Linfoglandular; anemia fal } \\
\text { ciforme concomitante }\end{array}$ & $\mathrm{P}$ \\
\hline 16-R.A.L.P. & 10 & 15 dias & Linfoglandular & $\mathrm{N}$ \\
\hline 17-L.S.R. & 15 & 5 anos & Linfoglandular & $\mathbf{N}$ \\
\hline 18.O.P. & 9 & 45 dias & Linfoglandular & $\mathbf{P}$ \\
\hline 19.M.C. & 47 & Indeterminado & Coriorretinite & $\mathbf{N}$ \\
\hline 20-M.N.S.J. & 6 & Indeterminado & Exame clínico normal & $\mathrm{N}$ \\
\hline
\end{tabular}

duraçāo das manifestaçōes clínicas e, sumàriamente, os tipos de toxoplasmose correspondentes aos individuos considerados.

Retiramos $2 \mathrm{ml}$ de saliva do assoalho bucal, agindo sempre em condições de esterilidade. Antes da inoculação, o material permaneceu em temperatura ambiente durante duas horas no máximo. Depois de adiçāo de $20 \mathrm{mg}$ de estreptomicina e, portanto, de $5 \mathrm{mg}$ a cada inóculo, injetamos $0,5 \mathrm{mI}$ de saliva em cada animal, para efetuar pesquisas do parasito sete e nove dias depois; em face a negatividade, executamos reinoculação, usando $1 \mathrm{ml}$ de exsudato peritoneal e recorrendo agora a apenas dois e näo a quatro camundongos, para praticar novos exames em oportunidades idênticas às referidas.

O Toxoplasma gondii foi sistemàticamente procurado, através de pesquisa a fresco, no líquido retirado, por aspiração, da cavidade peritoneal de animais prèviamente sacrificados, sendo conservados para pesquisas posteriores, referentes ao nono dia, dois e um camundongos, respectivamente, utilizados na tentativa inicial de isolamento do protozoário e na reinoculação. Empregamos como contrôles camundongos da mesma procedência que os demais, mas não inoculados com saliva; um dêles, em cada grupo de exames, mereceu investigação paralela, tendo resultado, dessa conduta, negatividade em tôdas as oportunidades.

\section{RESULTADOS}

Os resultados que obtivemos estão registrados no Quadro.

Verificamos estar presente o Toxoplasma gondii em $12(60 \%)$ das salivas submetidas a exames. A positividade decorreu da reinoculação no que concerne a cinco materiais (casos $\mathrm{n}^{\circ}{ }_{\mathrm{S}} 3,4,9,13$ e 18), uma vez que, quanto aos outros, mesmo sem adoção dêsse recurso, já evidenciamos o protozoário (casos n. ${ }^{\circ}$ s $1,2,5,6,8,10$ e 15) e dispensamos a segunda e complementar inoculação, a partir de líquido peritoneal dos camundongos originalmente usados.

\section{CCMENTÁRIOS}

Os fatos anteriormente mencionados permitem, acreditamos, a apresentação de alguns comentários. No entanto, apenas faremos menção a detalhes que consideramos fundamentais, pois estamos tão sòmente relatando informaçōes complementares a estudo prévio, cujos resultados já mereceram comunicaçāo; como estas novas observações não traduziram fatos bàsicamente diversos, é lícito considerar que se tornaram desnecessárias análises e deduçōes mais minuciosas.

1 - A presença do Toxoplasma gondii na saliva de $60 \%$ dos doentes com toxoplasmose por nós diagnosticados, confirma 
e amplia a constatação de Cathie (1), que deu origem ao nosso interêsse pelo assunto.

2 - Quando aumentamos a casuística utilizada, em relação à investigação anterior, na qual de dez doentes obtivemos saliva, consignamos um menor número de inaculações positivas; de qualquer forma, a. mais categórica percentagem de $60 \%$, concernente a indiscutíveis isolamentos do parasito, continua expressivamente a deixar em foco a secreção em aprêço como elementos capaz de permitir o diagnóstico etiológico como, ainda, de poder justificar a transmissão e disseminação da protozoose.

3 - indispensável salientar que dife- rentes facêtas ligadas à existência do Toxoplasma gondii na saliva de indivíduos com toxoplasmose justificam a oportuna abordagem de outros aspectos correlatos, tais como o tempo de sobrevida dos microorganismos eventualmente contidos nas secreções mantidas em diferentes condições, virulências dos protozoários isolados, suscetibilidades de pessoas expostas a êsse tipo de contágio, relação com as modalidades clínicas da infecção, influência de tentativas de tratamentos específicos e possível presença do agente parasitário em materiais de organismos infetados e não acometidos, obrigatòriamente, de toxoplasmose-doença, ativa ou recente.

\section{$S U M M A R Y$}

Through the intraperitoneal inoculation in mice the authors were able to show the presence of Toxoplasma gondii in the spittle of $12(60 \%)$ bearers of toxoplasmosis. The total number of studied patients was twenty.

This study represents a complement of a previous and preliminary one on the same subjetc.

The presence of the parasite in the saliva is stressed because of its significance in the transmission of the disease.

\section{BIBLIOGRAFIA}

1 - CATHIE, I.A.B. - Toxoplasma adenopathy in a child with isolation of the parasite. Lancet, $2: 115-116$, 1954.

2 - LEVI, G.C., HYAKUTAKE, S. AMATO NETO, V. \& CORREA, M.O.A.
- Presença 'do Toxoplasma gondii na saliva de pacientes com toxoplasmose. Eventual importância dessa verificação quanto à transmissão da doença (nota prévia). Rev. Inst. Med. Trop. São Paulo, 10: 54-58, 1968. 